This document is confidential and is proprietary to the American Chemical Society and its authors. Do not copy or disclose without written permission. If you have received this item in error, notify the sender and delete all copies.

\title{
Effect of Surface Charge on Surface-Initiated Atom Transfer Radical Polymerization from Cellulose Nanocrystals in Aqueous Media
}

\begin{tabular}{|r|l|}
\hline Journal: & Biomacromolecules \\
\hline Manuscript ID & bm-2016-00011q.R1 \\
\hline Manuscript Type: & Article \\
\hline Date Submitted by the Author: & $\mathrm{n}$ a \\
\hline Complete List of Authors: & $\begin{array}{l}\text { Zoppe, Justin; Ecole Polytechnique Fédérale de Lausanne (EPFL), Institute } \\
\text { of Materials, Polymers Laboratory } \\
\text { Xu, Xingyu; Ecole Polytechnique Fédérale de Lausanne (EPFL), Institute of } \\
\text { Materials, Polymers Laboratory } \\
\text { Känel, Cindy; Ecole Polytechnique Fédérale de Lausanne (EPFL), Institute } \\
\text { of Materials, Polymers Laboratory } \\
\text { Orsolini, Paola; EMPA, Applied Wood Materials } \\
\text { Siqueira, Gilberto; EMPA, Applied Wood Materials } \\
\text { Tingaut, Philippe; Swiss Federal Laboratories for Materials Science and } \\
\text { Technology (EMPA), } \\
\text { Zimmermann, Tanja; Empa, Wood Laboratory } \\
\text { Klok, Harm-Anton; Ecole Polytechnique Federale de Lausanne, Institut des } \\
\text { Materiaux, Laboratoire de Polymeres; Ecole Polytechnique Federale de } \\
\text { Lausanne, Institut des Materiaux, Laboratoire de Polymeres }\end{array}$ \\
\hline
\end{tabular}




\title{
Effect of Surface Charge on Surface- Initiated Atom Transfer Radical Polymerization from Cellulose Nanocrystals in Aqueous Media
}

\author{
Justin O. Zoppe,,$^{\dagger *}$ Xingyu Xu,,$^{\dagger}$ Cindy Känel,,$^{\dagger}$ Paola Orsolini, ${ }^{\ddagger}$ Gilberto \\ Siqueira, ${ }^{+}$Philippe Tingaut, ${ }^{+}$Tanja Zimmermann ${ }^{\dagger}$ and Harm-Anton Klok ${ }^{\dagger}$ \\ ${ }^{\dagger}$ Ecole Polytechnique Fédérale de Lausanne (EPFL) \\ Institut des Matériaux and Institut des Sciences et Ingénierie Chimiques, Laboratoire des \\ Polymères \\ STI - IMX - LP, MXD 036 (Bâtiment MXD) Station 12 \\ CH-1015 Lausanne, Switzerland \\ ${ }^{\ddagger}$ Empa, Swiss Federal Laboratories for Materials Science and Technology, Laboratory of Applied \\ Wood Materials, Überlandstrasse 129, CH-8600 Dübendorf, Switzerland
}

KEYWORDS: Cellulose nanocrystals (CNCs), surface-initiated controlled radical polymerization (SI-CRP), ATRP, SET-LRP, surface charge, electrical double layer, sulfate groups 


\begin{abstract}
Cellulose nanocrystals (CNCs) with different charge densities were utilized to examine the role of electrostatic interactions on surface-initiated atom transfer radical polymerization (SI-ATRP) in aqueous media. To this end, growth of hydrophilic uncharged poly $(N, N$-dimethylacrylamide $)$ (PDMAM) brushes was monitored by electrophoresis, ${ }^{1} \mathrm{H}$ NMR spectroscopy and dynamic light scattering (DLS). Molecular weight and polydispersity of PDMAM brushes was determined by GPC analysis of hydrolytically cleaved polymers. Initiator and polymer brush grafting densities, and thus, initiator efficiencies were derived from elemental analysis. Higher initiator efficiency of polymer brush growth was observed for CNCs with higher anionic surface sulfate half-ester group density, but at the expense of high polydispersity caused by inefficient deactivation. PDMAM grafts with number-average molecular weights up to $530 \mathrm{kDa}$ and polydispersity indices $<1.5$ were obtained under highly diluted monomer concentrations. The role of surface chemistry on the growth of neutral polymer brushes from CNCs in water is emphasized and a model of the interfacial region at the onset of polymerization is proposed. The results presented here could have implications for other substrates that present surface charges and for the assumption that the kinetics of $\mathrm{Cu}$-mediated SI-CRP are analogous to those conducted in solution.
\end{abstract}




\section{INTRODUCTION}

Surface-initiated controlled radical polymerization (SI-CRP), also known as reversible deactivation radical polymerization (SI-RDRP), is commonly employed to modify the properties of solid interfaces with polymer brushes. ${ }^{1-3}$ SI-CRP allows accurate control over polymer chain length, polydispersity and architecture. Among SI-CRP techniques, those mediated by transition metals, especially copper, are at the forefront due to their versatility, commercially available reagents and high tolerance toward many functional groups. SI-CRP is routinely utilized to graft polymer brushes from silica, gold, carbon, clay, metal and polymer substrates, some of which present charged surfaces.

There are a number of factors affecting $\mathrm{Cu}$-mediated $\mathrm{CRP}$ in water, such as high equilibrium constant $\left(\right.$ e.g. $\left.K_{A T R P}\right),{ }^{4,5} \mathrm{C}-\mathrm{X}$ bond hydrolysis, ${ }^{6}$ dissociation of $\mathrm{CuX}_{2} / \mathrm{L}$ complexes, ${ }^{7}$ and disproportionation of $\mathrm{CuX} / \mathrm{L}$ to $\mathrm{Cu}^{0}$ and $\mathrm{CuX}_{2} / \mathrm{L} \cdot{ }^{8-11}$ The latter has led to a rigorous debate over the mechanism of $\mathrm{Cu}$-mediated polymerization in the presence of $\mathrm{Cu}^{0}$, leading to different nomenclatures; single electron transfer living radical polymerization $(\mathrm{SET}-\mathrm{LRP})^{10,}{ }^{11}$ or supplemental activator and reducing agent atom transfer radical polymerization (SARA ATRP). 9, 12 While conventional atom transfer radical polymerization (ATRP) is activated by CuX, in SET-LRP/SARA ATRP, $\mathrm{Cu}^{0}$ also activates alkyl halides, resulting in ultrafast synthesis of ultrahigh molecular weight poly(meth)acrylates. Hence, $\mathrm{Cu}$-mediated CRP is commonly adopted as an umbrella term for ATRP and SET-LRP/SARA ATRP reactions.

The dissociation of $\mathrm{CuX}_{2} / \mathrm{L}$ complexes in aqueous systems is due to the high solubility of $\mathrm{CuX}_{2}$ salts, which can lead to inefficient deactivation of growing polymer chains. ${ }^{7}$ According to 
the DLVO theory, dissociation of functional groups at solid interfaces in polar media leads to an electrical double layer (EDL) of counterions as a result of electrostatic forces. ${ }^{13}$ The DebyeHückel model predicts that the Debye length $\left(\kappa^{-1}\right)$ of the EDL is inversely proportional to the ionic strength of an electrolyte solution, which plays a critical role in the stability of colloidal systems. Brooks et al. ${ }^{14-17}$ demonstrated that SI-CRP of $N, N$-dimethylacrylamide (DMAM) in the presence of $\mathrm{Cu}^{0}$ powder is facilitated by the presence of negative surface charges on polystyrene latex particles ${ }^{14-16}$ and poly(vinyl chloride) sheets. ${ }^{17}$ The authors proposed a model in which both $\mathrm{CuX}$ and $\mathrm{CuX}_{2}$ species were enriched at charged interfaces, leading to enhanced initiator efficiencies, higher monomer conversions and lower polydispersity in comparison to those synthesized in solution. ${ }^{14}$

Given that the solubility of $\mathrm{CuX}_{2}$ salts in water is orders of magnitude higher than $\mathrm{CuX}$, it can be assumed that the EDL in Cu-mediated SI-CRP systems consists primarily of divalent $\mathrm{Cu}^{2+} / \mathrm{L}$ and $\mathrm{X}^{-}$ions at equilibrium with $\mathrm{CuX}_{2} / \mathrm{L}$. Since the electrophoretic mobility $\left(\mu_{e}\right)$ of colloids depends on Debye length, ${ }^{18}$ monitoring this parameter could be a potentially useful tool to study the kinetics of $\mathrm{Cu}$-mediated SI-CRP in aqueous media. $\mu_{e}$ is simply a function of drift velocity and the applied electric field strength. From $\mu_{e}, \zeta$-potential is typically calculated based on the Smoluchowski model, but is only valid for small Debye lengths. Alternatively, the Hückel model is applied for thick EDLs resulting from very low ionic strength or those in organic media. Brooks $^{19,20}$ and Seaman ${ }^{20}$ showed that adsorption of neutral polymers onto cells and other charged particles led to predictable trends in $\zeta$-potential, due to changes in the Debye length caused by excluded volume at the interface. The relative $\zeta$-potential was also dependent on the concentration and molecular weight of adsorbed polymers. Furthermore, polyacrylamides are widely used as neutral, chemically inert media for polyacrylamide gel electrophoresis (PAGE). ${ }^{21}$ 
Inspired by the work of Brooks ${ }^{19,20}$ and $\operatorname{Seaman}^{20}$ on monitoring neutral polymer adsorption onto charged colloids via $\zeta$-potential, we hypothesized that electrophoresis could be applied to monitor neutral polymer brush growth (e.g. polyacrylamides) via $\mathrm{Cu}$-mediated SI-CRP from charged colloids in situ.

Cellulose nanocrystals (CNCs) are rod-shaped nanoparticles produced by acid hydrolysis of native cellulose fiber. ${ }^{22,} 23$ They exhibit unique properties, such as Young's modulus comparable to steel and self-assembly into chiral nematic liquid crystalline phases in a number of solvents. When sulfuric acid is utilized for CNC production, the resulting anionic surface sulfate half-ester groups provide exceptional colloidal stability. A growing number of researchers are focusing their efforts on surface modification of CNCs, due to their surface hydrophilicity that can hinder their dispersion in non-polar solvents and hydrophobic polymer matrices. ${ }^{24}$ Moreover, the surface charge density is easily tuned with acid- or base-catalyzed hydrolytic desulfation protocols $^{25,26}$ or by introducing cationic groups via etherification. ${ }^{27}$ While SI-CRP has been employed to graft polymer brushes from CNCs in organic media and water/alcohol mixtures, ${ }^{24}$ including $\quad$ polystyrene $^{28-30} \quad$ poly(tert-butyl $\quad$ acrylate) ${ }^{31} \quad$ poly(6-(4-(4methoxyphenylazo)phenoxy)hexyl methacrylate), ${ }^{32} \quad \operatorname{poly}(N, N$-dimethylaminoethyl methacrylate $),{ }^{33}$ poly $(N \text {-isopropylacrylamide })^{34-38}$ and copolymers of acrylic acid, ${ }^{38}$ the effect of surface charge on SI-CRP from CNCs in purely aqueous media has not yet been investigated. Herein, we grafted neutral poly(N,N-dimethylacrylamide) (PDMAM) brushes via SI-ATRP from CNCs with different surface densities of anionic sulfate half-ester groups. In contrast to the work of Brooks et al., ${ }^{14-17}$ in which SI-CRP was conducted with excess $\mathrm{Cu}^{0}$ powder, we chose to investigate polymerization conditions in which the $\mathrm{CuX} / \mathrm{CuX}{ }_{2}$ catalytic system would be mostly unaffected by disproportionation/comproportionation reactions. Besides influencing the 
concentration of electrolytes available to form an EDL through reduction of $\mathrm{CuX}_{2}$ species or comproportionation, ${ }^{8-11} \mathrm{Cu}^{0}$ particles would supply an undesired dispersed phase in addition to CNCs that might complicate in situ monitoring of polymer brush growth. Furthermore, in parallel with dynamic light scattering (DLS), in this study we also explored electrophoresis to observe the growth of neutral polymer brushes from CNCs substrates with different surface charge densities. The final chemical composition of the PDMAM grafted CNCs was confirmed by ATR-FTIR spectroscopy and elemental analysis. PDMAM brushes were then cleaved from CNC substrates by alkaline hydrolysis and molecular weight $\left(M_{n}\right)$ and polydispersity was determined by GPC analysis.

\section{EXPERIMENTAL SECTION}

Materials. Cotton fiber, $\alpha$-bromoisobutyryl bromide (BIBB), 4-dimethylaminopyridine (4DMAP), anhydrous dimethyl formamide (DMF), N,N-dimethylacrylamide (DMAM), dichloromethane (DCM), copper (I) chloride, copper (II) bromide, $N, N, N^{\prime}, N^{\prime \prime}, N^{\prime \prime}-$ pentamethyldiethylenetriamine (PMDETA), glycidyltrimethylammonium chloride (GTMAC), sulfuric acid (95\%), triethylamine (TEA, 99.5\%), acetone (99\%), ethanol (95\%), methanol (99\%), $\mathrm{NaCl}$ and $\mathrm{NaOH}$ pellets were all purchased from Sigma-Aldrich. Regenerated cellulose dialysis tubing (MWCO 3,500) was purchased from Spectrum ${ }^{\circledR}$ Labs. TEA was purified by distillation before use and DMAM was passed through a column of basic alumina to remove inhibitor. All other chemicals were used without further purification.

Production of cellulose nanocrystals (CNC-1). CNCs were extracted from cotton fiber by acid hydrolysis via $65 \mathrm{wt} \%$ aqueous sulfuric acid solution at $45{ }^{\circ} \mathrm{C}$ for 45 minutes at an acid-tocellulose pulp ratio of $16 \mathrm{~mL} / \mathrm{g}$. Caution: sulfuric acid solution is highly corrosive! The resulting 
dispersion of CNCs was diluted with deionized water and filtered into ice cubes to quench the hydrolysis reaction. CNCs were washed with deionized water by successive centrifugations at $8,000 \mathrm{rpm}$ at $4{ }^{\circ} \mathrm{C}$ for 15 minutes each. Subsequently, dialysis was carried out for one week against deionized water with a 3,500 MWCO dialysis membrane to remove residual sulfuric acid and byproducts. The concentration of the resulting $\mathrm{CNC}$ dispersions was calculated gravimetrically.

Calculation of average specific surface area (SSA) and surface charge density. CNCs extracted from cotton fiber with this procedure typically have a fraction of surface cellulose chains of 0.19 and each surface anhydroglucose unit (AGU) has an average of 1.5 reactive $-\mathrm{OH}$ groups. ${ }^{28,39}$ Considering the molecular dimensions of an AGU of $0.515 \times 0.515 \mathrm{~nm}^{2}$, the average specific surface area (SSA) was calculated to be $187 \mathrm{~m}^{2} / \mathrm{g}$, in close agreement with the recent SSA calculations by Lin and Dufresne ${ }^{40}$ of $191.2 \mathrm{~m}^{2} / \mathrm{g}$ considering an ellipsoidal cross-section model of cotton CNCs. A representative AFM height image of cotton CNCs is shown in Figure S1. Surface charge density of sulfate half-ester groups was determined by conductometric titration. $^{41}$

Removal of cellulose nanocrystal surface sulfate half-ester groups (CNC-2). Sulfate groups were hydrolytically cleaved from CNCs following established procedures. ${ }^{25,} 261 \%$ wt. dispersions of $\mathrm{CNCs}$ were treated in $1 \mathrm{M} \mathrm{NaOH}$ at $60{ }^{\circ} \mathrm{C}$ for 5 hours. Then, the reaction was quenched by a 10 -fold dilution with deionized water and centrifuged at $8,000 \mathrm{rpm}$ at $4{ }^{\circ} \mathrm{C}$ for 15 minutes. Consequently, desulfated CNCs were re-dispersed by sonication and dialyzed against deionized water for one week to remove traces of $\mathrm{NaOH}$. 
According to DLS measurements, the hydrodynamic size $\left(D_{H}\right)$ of CNC-2 was approximately twice that of CNC-1, therefore were likely aggregates of two, or not more than three, individual CNCs on average. ${ }^{42}$ Thus, a $\sim 25 \%$ loss of SSA was estimated giving $\sim 140 \mathrm{~m}^{2} / \mathrm{g}$. Average $D_{H}$ of CNC-1 and CNC-2 are shown in Figure S2.

Conductometric titration. After dialysis, CNC dispersions were diluted with deionized water to $0.1 \%$ wt. and $\mathrm{NaCl}$ was added to a final concentration of $1 \mathrm{mM} .^{41}$ Titrations were performed with a titrator 751 GPD Titrino (Metrohm AG, Herisau, Switzerland) by adding $0.02 \mathrm{~mL}$ of $0.1 \mathrm{M}$ $\mathrm{NaOH}$ at $30 \mathrm{~s}$ intervals while continuously stirring.

Synthesis of quaternary ammonium-functionalized cellulose nanocrystals (CNC-3). Quaternary ammonium-functionalized CNC preparation was adapted from previous work (Scheme S1). ${ }^{27,43}$ $\mathrm{NaOH}$ was added to a CNC-1 dispersion $(2.5 \%$ wt.) to a final concentration of 5 wt. $\% \mathrm{NaOH}$. GTMAC was added to the suspension at a ratio of 1.25:1 GTMAC : CNC hydroxyl group and the reaction was carried out at $65^{\circ} \mathrm{C}$ for 8 hours under stirring. The reaction mixture was neutralized with $\mathrm{HCl}$ and dialyzed against deionized water.

Initiator attachment to cellulose nanocrystal substrates CNC-1, CNC-2 and CNC-3. Surface hydroxyl groups of never-dried CNCs were reacted with BIBB catalyzed by 4-DMAP and TEA in DMF media. ${ }^{44}$ In a typical experiment, $0.5 \mathrm{~g}$ of CNCs $(0.586 \mathrm{mmol}$ of surface AGUs, equivalent to $0.880 \mathrm{mmol}$ reactive surface $-\mathrm{OH}$ groups) ${ }^{39}$ was solvent-exchanged from water to acetone to dry DMF by using successive centrifugation $\left(8,000 \mathrm{rpm}\right.$ at $4{ }^{\circ} \mathrm{C}$ for $\left.15 \mathrm{~min}\right)$ and sonication. Drops of saturated $\mathrm{NaCl}$ solution were added to aqueous $\mathrm{CNC}$ dispersions in the first step in order to facilitate pellet formation. The resulting CNCs were re-dispersed in $25 \mathrm{~mL}$ of dry DMF in a $50 \mathrm{~mL}$ Schlenk flask containing $0.462 \mathrm{mmol}$ 4-DMAP under a nitrogen atmosphere 
and continuous stirring at ambient temperature. Then, $4.62 \mathrm{mmol}$ of TEA was slowly added, followed by drop wise addition of $4.62 \mathrm{mmol}$ of BIBB. The dispersion was left to react for $24 \mathrm{~h}$ at ambient temperature and then collected by centrifugation. The DMF supernatant was removed and initiator-modified CNCs (ini-CNCs) were re-dispersed by shaking/sonication in DCM and collected again by centrifugation. This process was repeated with ethanol before dialysis against deionized water ( $\mathrm{pH}$ 6.8) for 2 days. After dialysis, never-dried ini-CNCs were used directly for the following SI-ATRP experiments, thus $\mathrm{H}^{+}$counterions accompanied sulfate half-ester groups.

\section{SI-ATRP of N,N-dimethylacrylamide from initiator-modified CNC-1, CNC-2 and CNC-3} substrates. $100 \mathrm{~mL}$ of $0.1 \%$ wt. aqueous dispersions of ini-CNCs (CNC-1, CNC-2 or CNC-3) were placed in $100 \mathrm{~mL}$ Schlenk flasks containing $0.0636 \mathrm{mmol}^{\mathrm{CuBr}_{2}}$ with a stir bar. Polymerizations were carried out with a ratio of 100:1:0.3:2 DMAM:CuCl:CuBr $2: \mathrm{PMDETA}$ First, 2 g (20.2 mmol) of purified DMAM was injected into to flask via syringe, followed by 0.403 mmol PMDETA. This solution was then bubbled with nitrogen via syringe needle for $1 \mathrm{~h}$, after which $0.202 \mathrm{mmol} \mathrm{CuCl}$ was added under a nitrogen blanket to initiate polymerization. Samples of the reaction media were collected at $5 \mathrm{~min}$ increments during the first $4 \mathrm{~h}$ for ${ }^{1} \mathrm{H}$ NMR, DLS and electrophoresis to obtain monomer conversions, hydrodynamic diameter $\left(D_{H}\right)$ and electrophoretic mobility $\left(\mu_{e}\right)$, respectively. The solution was left to react until $22 \mathrm{~h}$ at ambient temperature before being subjected to dialysis against deionized water until neutral $\mathrm{pH}$ was reached. FTIR spectra of DMAM monomer compared to PDMAM brushes are shown in Figure S4.

Cleavage of polymer brushes via alkaline hydrolysis. $60 \mathrm{mg}$ of freeze-dried samples of PDMAM grafted CNC-1, CNC-2 and CNC-3 were each placed in a flask containing $10 \mathrm{~mL}$ of $2 \%$ wt. $\mathrm{NaOH}$ while stirring at ambient temperature. This mixture was left to react for $48 \mathrm{~h}$, followed by 
centrifugation at $8,000 \mathrm{rpm}$ at $4{ }^{\circ} \mathrm{C}$ for 15 minutes. Subsequently, the supernatant containing cleaved PDMAM was collected and dialyzed against deionized water until neutral pH was reached. Purified PDMAM solutions were freeze-dried for GPC and FTIR analysis. FTIR spectra of cleaved PDMAM and DMAM monomer are shown in Figure S5.

Atomic Force Microscopy (AFM). Cellulose nanocrystal dispersions were spin-coated onto UV/ozone-treated silicon wafers with an anchoring polyethyleneimine (PEI) layer at 4,000 rpm. After deposition, the substrate was spun for $30 \mathrm{~s}$. The surfaces were then dried at $80{ }^{\circ} \mathrm{C}$ for $1 \mathrm{~h}$. The spin-coated CNC films were imaged using a scanning probe microscope (Multimode Nanoscope IIIa, Digital Instruments) in tapping mode with non-coated silicon-etched probes (model LTESP, Veeco) with a nominal spring constant of $48 \mathrm{~N} / \mathrm{m}$.

${ }^{1} \boldsymbol{H}$ NMR. Spectra were obtained from samples in $\mathrm{D}_{2} \mathrm{O}$ at room temperature from a Bruker AVANCE-400 Ultra Shield spectrometer with Topshim software and processed using ACDLabs ${ }^{1} \mathrm{H}$ NMR processor academic edition. Samples were taken from the polymerization media at different time points to monitor the disappearance of the ethenyl proton doublet in the range of $\delta$ $=6.15-5.95 \mathrm{ppm}$. The evolution of monomer conversion with time was obtained from

$$
\alpha=1-\frac{[M]_{t}}{[M]_{0}}
$$

where $\alpha$ is the monomer conversion, $[\mathrm{M}]_{t}$ is the monomer concentration at time $t$ and $[\mathrm{M}]_{0}$ is the monomer concentration prior to addition of catalyst.

Gel permeation chromatography. GPC was conducted on a GPC 50+ Agilent system with a Milli-Q water eluent with $10 \% \mathrm{MeOH}$ at $1 \mathrm{~mL} \mathrm{~min}^{-1}$ at $40{ }^{\circ} \mathrm{C}$. The system was equipped with a 
refractive index detector and guard column $+2 \mathrm{x}$ PL-aquagel-OH Mixed M. The instrument was calibrated with narrow polydispersity PEG standards from 454 to $1010 \mathrm{~kg} \mathrm{~mol}^{-1}$.

Attenuated Total Reflectance-Fourier Transform Infrared Spectroscopy (ATR-FTIR). Infrared spectra were obtained from freeze-dried CNC samples were placed directly in a Nicolet 6700 FTIR spectrometer equipped with a diamond Smart iTR accessory. All spectra were collected with a $4 \mathrm{~cm}^{-1}$ resolution after 32 continuous scans.

Dynamic light scattering (DLS), Electrophoresis and Conductivity. Aqueous dispersions of CNC samples in disposable cuvettes were analyzed in a Malvern Zetasizer Nano ZS with a detection angle of $173^{\circ}$ at room temperature with no added electrolytes, other than those formed by the copper halide catalysts used for SI-ATRP. All measurements were performed using a refractive index of 1.470 for cellulose. Hydrodynamic diameter values reported represent the diameter of equivalent spherical particles with the same translational diffusion coefficient. ${ }^{45}$ Electrophoretic mobility and conductivity measurements were carried out in disposable folded capillary cells. In the case of in situ measurements, capillary cells were flushed with nitrogen and sealed with septa prior to injection of samples via syringe. All values reported are the average of three measurements.

Elemental Analysis. The determination of C, N, S and Br contents was achieved by elemental analysis (Laboratorium für Organische Chemie, ETH-Zürich, Switzerland). The combustion products derived after the samples' digestion - $\mathrm{CO}_{2}, \mathrm{CO}$, and $\mathrm{SO}_{2}$, respectively for $\mathrm{C}$ and $\mathrm{S}$ - were analyzed by infrared spectroscopy. $\mathrm{N}_{2}$ was determined on the basis of conductivity measurements. Br content was evaluated following the Schöniger method; $\mathrm{Br}$ is absorbed in a liquid medium and eventually determined by titration. 
Thermogravimetric analysis (TGA). Freeze-dried CNC samples were subjected to TGA analysis in a PerkinElmer TGA 4000. 2-5 mg of samples were placed in ceramic pans and weight loss was monitored from 30 to $600{ }^{\circ} \mathrm{C}$ at a rate of $10{ }^{\circ} \mathrm{C} / \mathrm{min}$ under a nitrogen flow rate of $20 \mathrm{~mL} / \mathrm{min}$. TGA curves of CNC samples are shown in Figure S6.

\section{RESULTS \& DISCUSSION}

Scheme 1 summarizes the different steps involved in the growth and cleavage of PDMAM brushes from CNC substrates. The experiments in this study were performed with two CNC substrates with different surface charge densities $\left(\sigma_{s}\right)$. The surface charge densities were determined from conductometric titrations, ${ }^{41}$ however without the use of a strong acid cationexchange resin to ensure full protonation of CNC samples. ${ }^{46}$ A first substrate with a sulfate halfester content of $0.22 \mathrm{meq} / \mathrm{g}$, or $0.7 \mathrm{e} / \mathrm{nm}^{2}(\mathrm{CNC}-1)$ was prepared by sulfuric acid hydrolysis of cotton fiber following established protocols. ${ }^{41}$ A representative AFM image of these CNCs is shown in Figure S1 in Supporting Information. Cotton CNC dimensions varied from 100-250 nm in length and 3-7 $\mathrm{nm}$ in width. The second substrate, with a sulfate half-ester content of 0.04 $\mathrm{meq} / \mathrm{g}$ or $0.1 \mathrm{e} / \mathrm{nm}^{2}$ (CNC-2), was prepared by partial hydrolytic cleavage of surface sulfate groups from $\mathrm{CNC}-1$ with $\mathrm{NaOH}$ at $60^{\circ} \mathrm{C} .{ }^{25,26}$ It should be clarified that since $\mathrm{CNC}-1$ and $\mathrm{CNC}-2$ substrates were not passed through a strong acid cation-exchange resin after dialysis and prior to conductometric titrations, ${ }^{46}$ surface charge densities should only be considered comparatively and not as absolute values. Nevertheless, recent $\zeta$-potential and TGA measurements of desulfated CNCs treated under the same conditions in our laboratory correspond to an efficient reduction of surface sulfate half-ester groups ${ }^{47}$ Results of elemental analysis are shown in Table S1. Large discrepancies in surface sulfate half-ester content are commonly observed between measurements conducted by elemental analysis and conductometric titrations. ${ }^{46}$ Although likely affected by 
sample preparation, previous elemental analysis ${ }^{48}$ and $\mathrm{XPS}^{47,}{ }^{48}$ studies have shown that significant amounts of sulfur remain in "desulfated" CNCs that is also found in cotton cellulose raw materials and CNCs produced by hydrochloric acid hydrolysis. For example, Gu et al. ${ }^{48}$ found $0.13 \%$ sulfur in cotton cellulose raw materials used to make CNCs. This remaining sulfur is probably derived from other plant tissues essential for plant biosynthesis in a different chemical state and not surface sulfate half-ester groups. Therefore, we relied on conductometric titrations, ${ }^{41}$ TGA, DLS and electrophoresis to determine the differences in surface charge density and not elemental analysis of overall sulfur content, which is more sensitive to impurities if free sulfur-containing molecules or residual sulfuric acid are present. Figure S2 shows the hydrodynamic diameter $\left(D_{H}\right)$ of CNCs measured by DLS before $(\mathrm{CNC}-1=120 \mathrm{~nm})$ and after hydrolytic desulfation $(\mathrm{CNC}-2=330 \mathrm{~nm}$ ), indicating that CNC-2 were aggregates of $\sim 2-3 \mathrm{CNCs}$. These results agreed well with the fractal dimensions of desulfated CNC aggregates determined by small-angle neutron scattering (SANS). ${ }^{42}$

Scheme 1. Synthesis of poly $(N, N$-dimethylacrylamide $)$ brushes from cellulose nanocrystals and brush cleavage via alkaline hydrolysis.
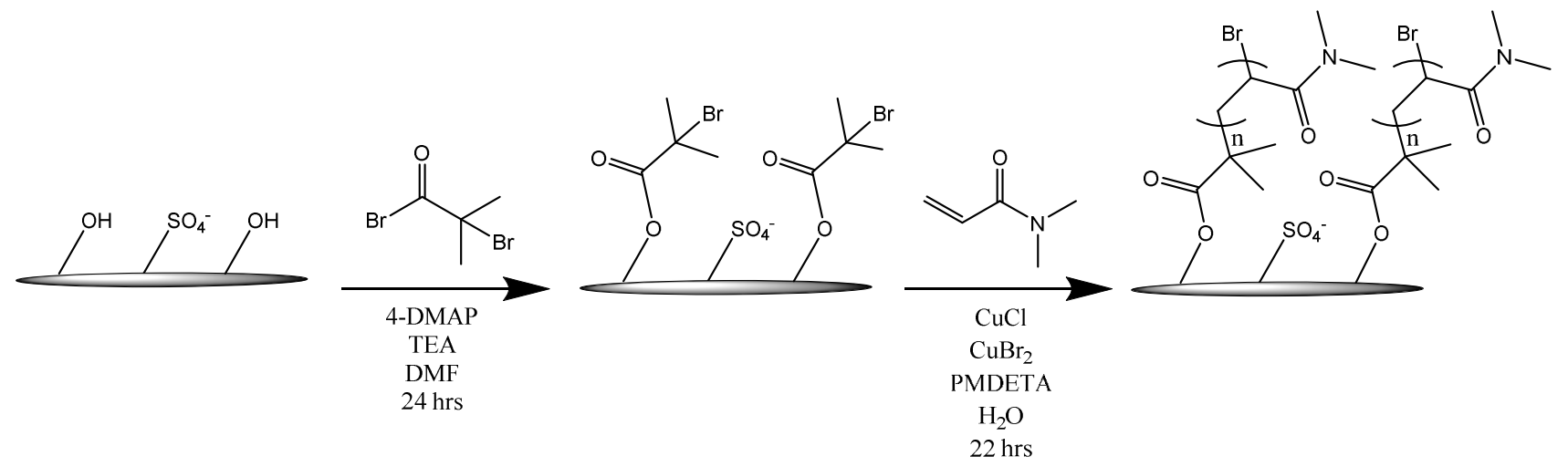


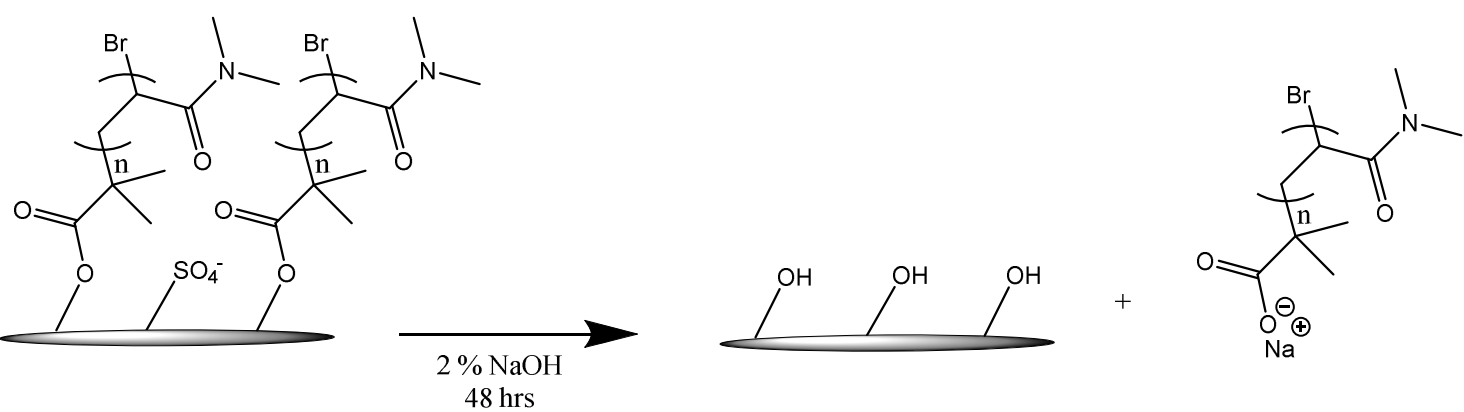

Following extensive dialysis of $\mathrm{CNC}-1$ and $\mathrm{CNC}-2$ against deionized water, $\alpha$ bromoisobutyryl bromide (BIBB) was grafted to both substrates under identical conditions by 4dimethylaminopyridine-catalyzed esterification of surface hydroxyl groups. ${ }^{44}$ At first, $\mathrm{CNC}-1$ and CNC-2 were solvent-exchanged from water to acetone to dry DMF through successive centrifugations. After purification by dialysis against deionized water, initiator-modified CNCs (ini-CNCs) were lyophilized and $\mathrm{C}=\mathrm{O}$ peaks, reflecting the successful attachment of the ATRP initiator, were observed in the range of $1750-1715 \mathrm{~cm}^{-1}$ by FTIR (Figure S3). Elemental analysis resulted in $\mathrm{Br}$ contents of $0.04 \%$ and $0.22 \%$ for ini-CNC-1 and ini-CNC-2, respectively (Table $\mathrm{S} 1)$. This difference in $\mathrm{Br}$ content reflects the difference in the number of available surface hydroxyl groups between $\mathrm{CNC}-1$ and $\mathrm{CNC}-2$, due to the effect of hydrolytic desulfation. ${ }^{25,} 26$ Initiator and, subsequently, polymer brush grafting densities were calculated from changes in bromine and carbon content, respectively, based on equations provided elsewhere. ${ }^{28,} 49$ Considering the theoretical grafting density calculations provided by Morandi et al. ${ }^{28}$ and the molecular dimensions of an anhydroglucose unit of $0.515 \times 0.515 \mathrm{~nm}^{2}$, initiator grafting density $\left(\sigma_{i}\right)$ was calculated to be 0.02 and $0.1 \mathrm{molec} . / \mathrm{nm}^{2}$ for CNC-1 and CNC-2, respectively (Table 1$)$. The initiator grafting densities are sufficiently low to rule out effects of the growing "viscous front" determined by Behling et al., ${ }^{50}$ in which brushes with a grafting density exceeding 1 chain $/ \mathrm{nm}^{2}$ cause high local viscosity at the solid-liquid interface and thus, influence the kinetics 
of SI-ATRP. Therefore, we assume that differences in the kinetics of SI-ATRP are unaffected by grafting density. Moreover, since previously reported surface initiator efficiencies were typically between $5-65 \%,{ }^{14,15,17}$ the resulting tethered polymers would likely be below the "brush" regime. ${ }^{51}$ For ease of discussion, however, polymers grafted from both $\mathrm{CNC}$ substrates will be referred to as "brushes" throughout this manuscript. Together with the surface charge density, which is also listed in Table 1, these initiator grafting densities indicated a large excess of negative surface charges relative to ATRP initiator sites for CNC-1, whereas CNC-2 presented anionic surface charges and ATRP initiator sites in essentially equimolar quantities. These substrates were subsequently used to evaluate the effect of negative surface charge on SI-ATRP of DMAM. 
Table 1. Summary of the results of SI-ATRP of DMAM from substrates CNC-1 and CNC-2, including surface charge density $\left(\sigma_{s}\right)$, monomer conversions, relative compositions, molecular weight $\left(M_{n}, M_{w}\right)$ and polydispersity $\left(M_{w} M_{n}\right)$ of PDMAM brushes, initiator $\left(\sigma_{i}\right)$ and PDMAM grafting densities $(\sigma)$ and initiator effiencies $\left(\sigma / \sigma_{i}\right)$.

\begin{tabular}{|c|c|c|c|c|c|c|c|c|c|c|}
\hline Substrate $^{\mathrm{a}}$ & $\begin{array}{c}\sigma_{s} \\
\left(e / \mathbf{n m}^{2}\right)^{b}\end{array}$ & $\begin{array}{c}\text { DMAM } \\
\text { conversion } \\
(\%)^{c}\end{array}$ & $\begin{array}{c}\% \\
\text { PDMAM } \\
(\% \text { wt. })^{d}\end{array}$ & $\begin{array}{l}\% \text { CNC } \\
(\% \text { wt. })^{d}\end{array}$ & $\begin{array}{c}M_{n} \\
(\mathbf{k D a})^{\mathrm{e}}\end{array}$ & $\begin{array}{c}M_{w} \\
(\mathbf{k D a})^{\mathrm{e}}\end{array}$ & $\begin{array}{c}M_{w} / M_{n} \\
(-)^{e}\end{array}$ & $\begin{array}{c}\sigma_{i} \\
\left(\mathrm{molec} . / \mathbf{n m}^{2}\right)^{\mathrm{f}}\end{array}$ & $\begin{array}{c}\sigma \\
\left(\text { chains } / \mathbf{n m}^{2}\right)^{\mathrm{f}}\end{array}$ & $\begin{array}{c}\sigma / \sigma_{i} \\
(-)\end{array}$ \\
\hline CNC-1 & 0.7 & 19 & 79 & 21 & 420 & 640 & 1.5 & 0.02 & 0.002 & 0.10 \\
\hline $\mathrm{CNC}-2$ & 0.1 & 11 & 69 & 31 & 530 & 780 & 1.4 & 0.1 & 0.002 & 0.02 \\
\hline
\end{tabular}

${ }^{a}$ Polymerization conditions: $0.1 \%$ wt. ini-CNCs, $2 \%$ wt. DMAM, $2.0 \mu \mathrm{mol} / \mathrm{mL} \mathrm{CuCl}, 0.61 \mu \mathrm{mol} / \mathrm{mL} \mathrm{CuBr}, 4.0 \mu \mathrm{mol} / \mathrm{mL}$ PMDETA, $100 \mathrm{~mL}$ $\mathrm{H}_{2} \mathrm{O}, 22 \mathrm{~h}$, ambient temperature

${ }^{b}$ Determined from conductometric titrations of CNCs before and after desulfation considering an average specific surface area of $187 \mathrm{~m}^{2} / \mathrm{g}$ and where $e$ denotes elementary charge (see Experimental Section)

${ }^{\mathrm{c}}$ Determined by ${ }^{1} \mathrm{H}$ NMR

${ }^{\mathrm{d}}$ Determined from monomer conversions

e Determined by GPC of cleaved PDMAM brushes calibrated with PEG standards

fDetermined from elemental analysis considering an average specific surface area of $187 \mathrm{~m}^{2} / \mathrm{g}$ for CNC-1 and $140 \mathrm{~m}^{2} / \mathrm{g}$ for CNC-2 (see Experimental Section)

PDMAM grafts were grown from ini-CNC-1 and ini-CNC-2 in water using a catalytic system composed of $\mathrm{CuCl}: \mathrm{CuBr}_{2}:$ PMDETA $(3: 1: 6)$. The first report on ATRP of $N, N$ dimethylacrylamide (DMAM) with a $\mathrm{CuBr}: \mathrm{Me}_{4}$ Cyclam catalytic system in aqueous solution demonstrated that $100 \%$ conversion is achieved within one minute at room temperature, but with lack of control. ${ }^{52}$ This was likely affected by the absence of $\mathrm{CuX}_{2}$ deactivator and disproportionation of $\mathrm{CuX} / \mathrm{L}$ species. ${ }^{53}$ As SI-ATRP of DMAM from CNCs with CuCl:PMDETA was also expected to occur rapidly, $\mathrm{CuBr}_{2}$ was added as deactivator and thus, halide-exchange (HE) was used in attempts to better control the polymerization. ${ }^{54}$ Furthermore, disproportionation of $\mathrm{CuCl} / \mathrm{L}$ is very slow in aqueous media, even in the presence of tetradentate ligands, such as $\mathrm{Me}_{6} \mathrm{TREN}^{53}$ Therefore, we expected that generation of $\mathrm{Cu}^{0}$ particles via disproportionation can be avoided under these reactions conditions such that the reaction proceeds via an SI-ATRP mechanism. SI-ATRP of DMAM from initiator modified CNC-1 and CNC-2 was conducted under diluted conditions (i.e. $0.1 \%$ wt. ini-CNCs and $2 \%$ wt. or $0.2 \mathrm{M}$ DMAM) so that the 
polymerization media could be analyzed directly by DLS and electrophoresis without further dilution. It should also be emphasized that all polymerizations were carried out in the absence of sacrificial initiators for similar reasons. Since $\mu_{e}$ also depends on the viscosity $(\eta)$ of the dispersant, in this case water, such a low monomer concentration would have a negligible effect. Based on the elemental analysis results of initiator-modified CNCs (Table S1), the target degree of polymerization (DP) was calculated to be 32000 and 8800 for CNC-1 and CNC-2, respectively. Maximum monomer conversions (11-19\%) were reached within 5-10 minutes of polymerization for both CNC-1 and CNC-2 based on ${ }^{1} \mathrm{H}$ NMR spectroscopy (Table 1), as previously observed in aqueous solution. ${ }^{52}$ The low overall monomer conversion observed was probably due to the absence of sacrificial initiator and the diffusion limitations of such dilute reactant concentrations. It is interesting to note that the monomer conversion obtained for CNC-1 (19\%) was nearly twice that of CNC-2 (11\%), probably because of higher effective surface area of the CNC-1 sample compared to CNC-2 that were shown to slightly aggregate (Figure S2 and 1B). To clarify the effects of aggregation on SI-ATRP from CNC-2, the same experiments were attempted using quaternary ammonium-functionalized CNCs (CNC-3) (Scheme 2), however with limited success and to be discussed later. The presence of PDMAM brushes was confirmed by an intense amide peak at $1614 \mathrm{~cm}^{-1}$ in FTIR spectra, seen in Figure S3. FTIR spectra of the DMAM monomer compared to PDMAM grafted CNC-1 is shown in Figure S4, which confirmed the absence of adsorbed monomer. In attempts to determine overall compositions of PDMAM grafts and CNCs, TGA was conducted and weight loss curves of each sample and degradation onsets are shown Figure S6. As expected, CNC-2 samples prior to polymer grafting were thermally stable up to temperatures $\sim 65^{\circ} \mathrm{C}$ higher than $\mathrm{CNC}-1$, due to removal of sulfate half-ester groups that catalyze thermal degradation. ${ }^{40,47}$ Although we were unable to resolve PDMAM grafts and CNCs in the weight loss curves, the degradation onsets clearly showed increased thermal stability 
upon polymer grafting from both $\mathrm{CNC}-1$ and $\mathrm{CNC}-2$. From the maximum monomer conversions determined by ${ }^{1} \mathrm{H}$ NMR spectroscopy (Table 1), the relative composition of PDMAM grafts was calculated to be $79 \%$ for $\mathrm{CNC}-1$ and $69 \%$ for $\mathrm{CNC}-2$, thus the grafted CNC samples consisted mostly of PDMAM.

Growth of PDMAM brushes from CNC-1 and CNC-2 could be monitored by DLS (Figure 1). Here, the reported hydrodynamic diameter $\left(D_{H}\right)$ of the rod-shaped particles is that of an equivalent sphere with the same translational diffusion coefficient. ${ }^{45}$ The initial $D_{H}$ of CNC-1 was $120 \mathrm{~nm}$, which did not change after attachment of the initiator nor in the presence of $\mathrm{CuBr}_{2} / \mathrm{PMDETA} / \mathrm{DMAM}$ (Figure 1A). However, after $\mathrm{CuCl}$ was added to start the polymerization reaction, a stark increase in $D_{H}$ on the order of $400 \mathrm{~nm}$ was observed after a reaction time of only 5 minutes. This did not change significantly, even after 22 hours. A similar trend is shown in Figure 1B, but with a slightly larger initial $D_{H}(250 \mathrm{~nm})$ due to the slight aggregation of $\mathrm{CNC}-2$. This was expected since $\mathrm{CNC}-2$ presented a lower surface density of anionic sulfate-half ester groups and thus was more prone to aggregate. Based on the observed $D_{H}$, these aggregates were estimated to consist of 2-3 CNCs, which was considered for grafting density calculations.

Since CNC-2 samples were slightly aggregated during SI-ATRP experiments, CNCs were also modified with cationic quaternary ammonium groups (CNC-3) in attempts to form more stable dispersions for subsequent SI-ATRP (Scheme 2). The success of the reaction was confirmed by FTIR (Figure S9), in which a new shoulder at $1480 \mathrm{~cm}^{-1}$ appeared, as well as changes in the peak intensities in the $1100-900 \mathrm{~cm}^{-1}$ region. ${ }^{43}$ DLS measurements of CNC-3 were carried out, however unsuccessfully, since these samples aggregated to a large extent, even after multiple sonication steps, which was also visible to the naked eye. Therefore, the SSA of CNC-3 
could not be accurately determined for the calculation of surface charge density. Previous work by Hasani et al. ${ }^{27}$ found that CNCs modified with GTMAC had much lower (cationic) surface charge density than the CNC starting materials containing sulfate half-ester groups. These conditions are even harsher than those used for hydrolytic desulfation, ${ }^{25,}{ }^{26}$ such that lower colloidal stability of CNC-3 might have been expected. Subsequently, initiator modified CNC-3 substrates aggregated to an even greater extent than $\mathrm{CNC}-2$, such that their hydrodynamic diameter $\left(D_{H}\right)$ could not be successfully monitored by DLS during SI-ATRP of DMAM. Although cationic groups were successfully attached to CNCs (Figure S9), we suspected that the overall surface charge was insufficient to produce stable colloidal dispersions. ${ }^{27}$ Regardless, a maximum monomer conversion of $16 \%$ was also reached within 5-10 minutes with CNC-3 substrates as determined by ${ }^{1} \mathrm{H}$ NMR.
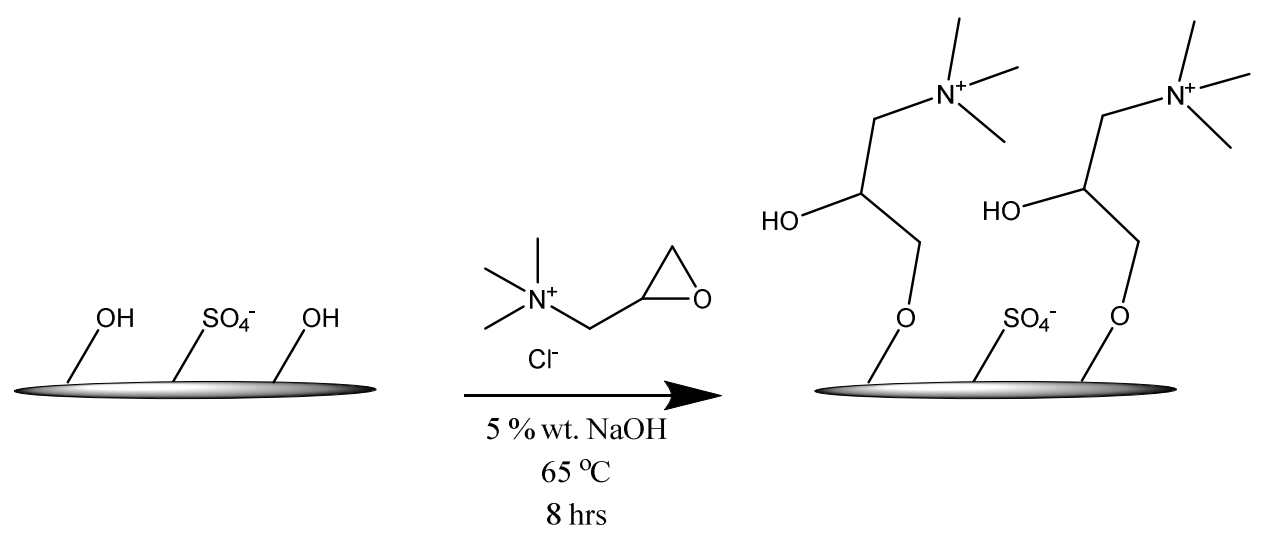

Scheme 2. Etherification of CNC surface hydroxyl groups with GTMAC to form quaternary ammonium-functionalized CNCs (CNC-3). 

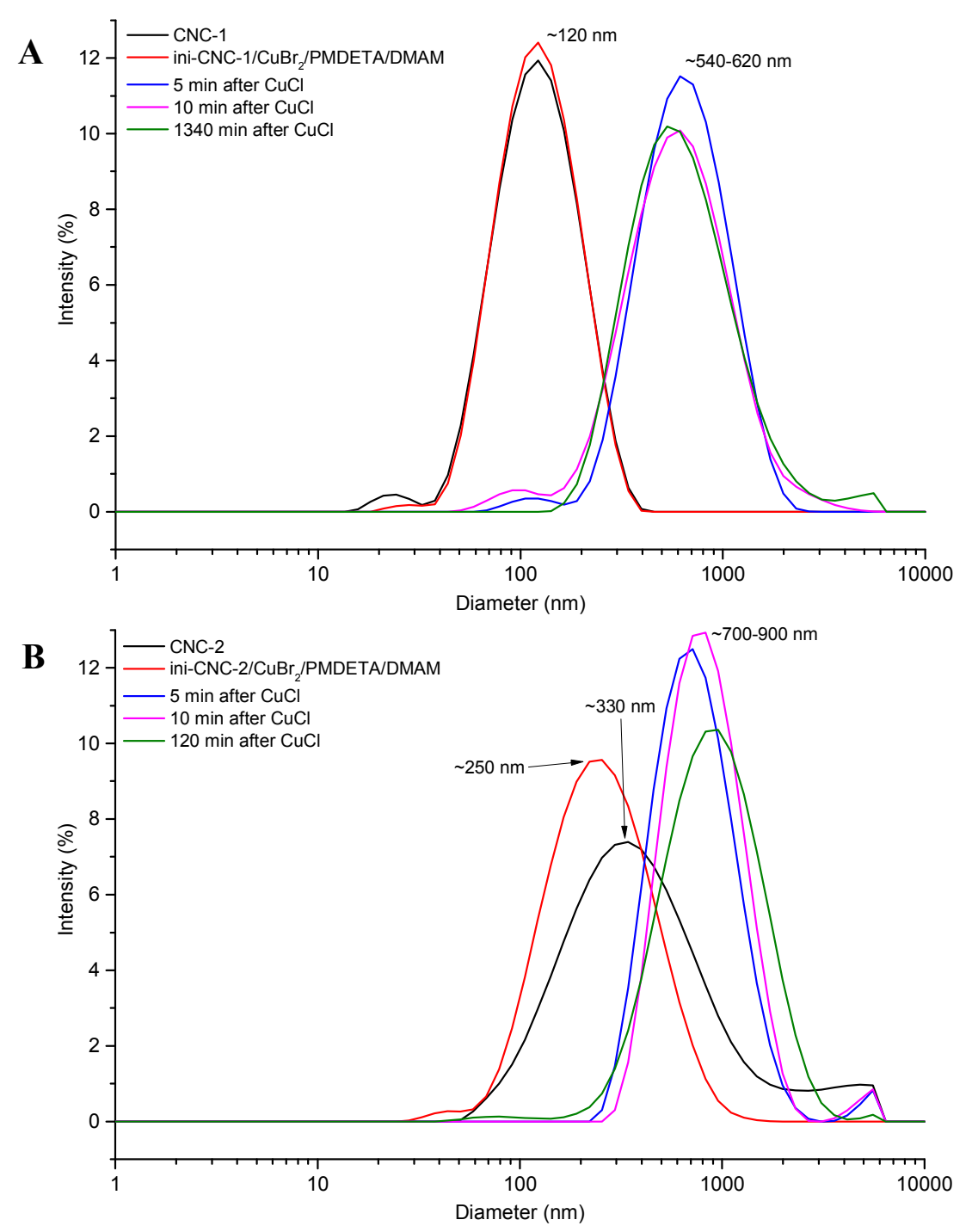

Figure 1. Hydrodynamic diameter $\left(D_{H}\right)$ of CNC-1 (A) and CNC-2 (B) before and after attachment of the ATRP initiator, as well as the presence of the ATRP catalytic system and during polymer brush growth.

One of the objectives of this study was to utilize electrophoresis to monitor polymer brush growth. Figure 2 shows the evolution of $\mu_{e}$ as a function of polymerization time during the growth of PDMAM brushes from ini-CNC-1 and ini-CNC-2. At first, the $\mu_{e}$ of ini-CNCs was measured after extensive dialysis against deionized water with no added salts. The higher $\mu_{e}$ of 
the ini-CNC-1 substrate (more negative value) is a result of higher anionic charge density. At such low ionic strengths, as in the case of deionized water, an infinitely thick EDL is formed, thus complicating interpretations of $\mu_{e}$. Therefore, we considered $t=0$ to be the CNC dispersions containing $\mathrm{CuBr}_{2}$, PMDETA and DMAM monomer before the addition of $\mathrm{CuCl}$. As shown in Figure $2, \mu_{e}$ decreased for both substrates after addition of monomer, ligand and deactivator, since the EDL was compressed by increased ionic strength and anionic surface charges were neutralized by cationic counterions. Also, after addition of $\mathrm{CuBr}_{2}$, PMDETA and DMAM, the ini-CNC-1 substrate showed higher $\mu_{e}$ as compared to the CNC-2 counterpart. During SI-ATRP, samples were taken from the reaction media after $5 \mathrm{~min}$ and up to $22 \mathrm{~h}$. Five minutes after addition of $\mathrm{CuCl}$ activator, $\mathrm{CNC}-\mathrm{g}$-PDMAM-1 showed values approaching zero at all points measured in time, in agreement with maximum monomer conversions determined by ${ }^{1} \mathrm{H}$ NMR spectroscopy after 5 min (see Table 1). This was interpreted as a combination of viscosity-related drag and the insulating effect of the electrically inert polymer brush layer that nearly completely immobilized charged CNCs in the presence of an electric field. On the other hand, CNC-gPDMAM-2 reached a plateau at $c a .-0.20 \mu \mathrm{mcm} / \mathrm{Vs}$ after $1 \mathrm{~h}$, suggesting their remaining mobility in the electric field, or inefficient insulation by the polymer brush layer. Since CNC-2 were determined to have significantly lower surface charge density than $\mathrm{CNC}-1,{ }^{41}$ this could have been due to the larger particle size of CNC-g-PDMAM-2, meaning their mobility was less affected by the cloud of counterions in the EDL at such low electrolyte concentrations. ${ }^{55}$ On the other hand, $\mu_{e}$ is also affected by the orientation of rod-shaped particles due to preferential alignments, ${ }^{56}$ challenging direct interpretations. Interestingly, $\mu_{e}$ of CNC-g-PDMAM-2 did not reach a maximum until $60 \mathrm{~min}$., in contrast to the maximum monomer conversion that was observed by ${ }^{1} \mathrm{H}$ NMR after only $10 \mathrm{~min}$. This could be a potential indication of higher sensitivity of the electrophoresis measurement, but further investigations are required, especially to address the 
effect of $\mathrm{CNC}$ orientation on electrophoretic mobility. As discussed above, quaternary ammonium-functionalized $\mathrm{CNC}-3$ substrates aggregated to an even greater extent than $\mathrm{CNC}-2$ and had an electrophoretic mobility only within the small range $-1<\mu_{e}<0 \mu \mathrm{mcm} / \mathrm{Vs}$, thus could not be used to monitor SI-ATRP of DMAM.

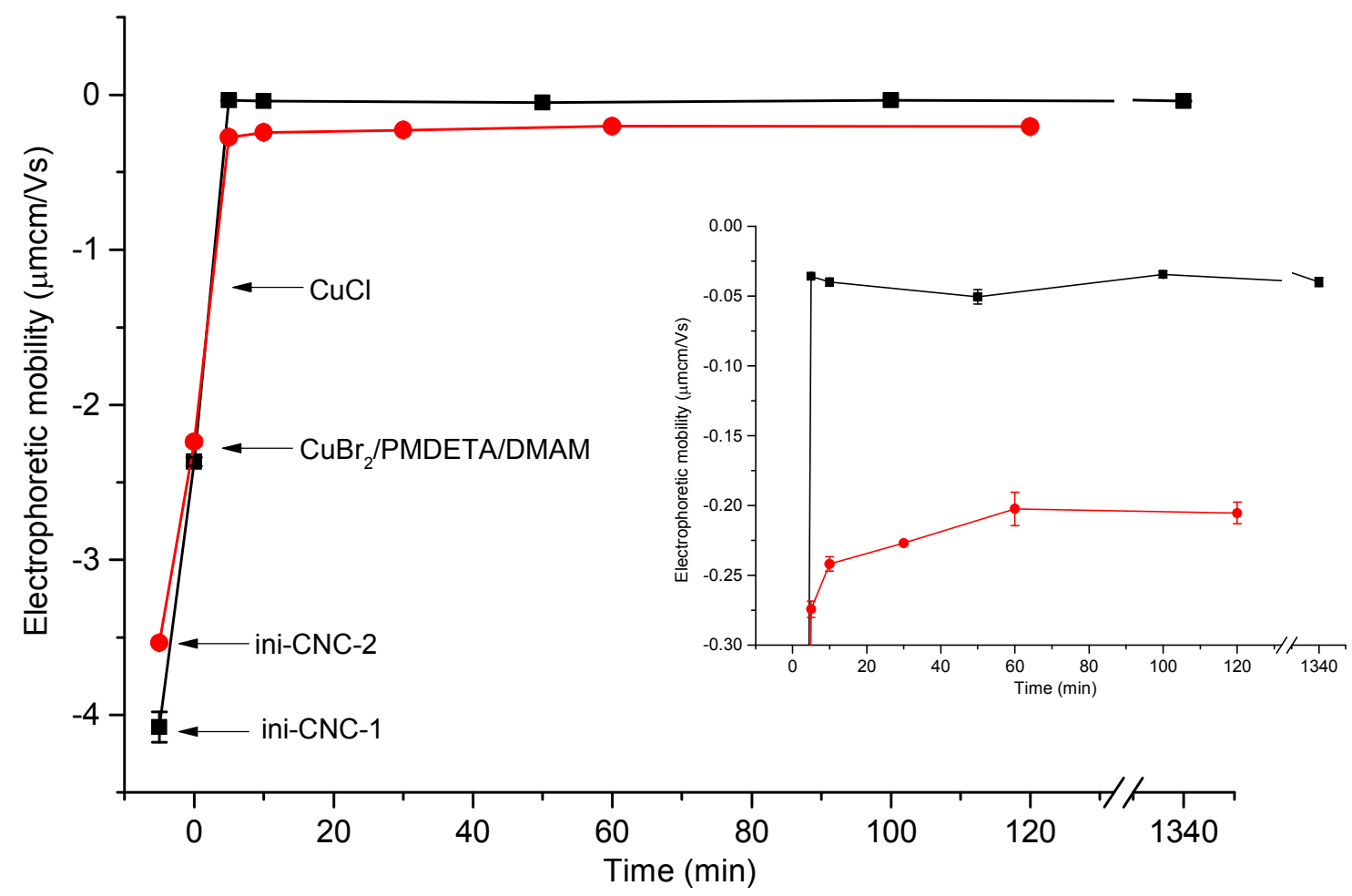

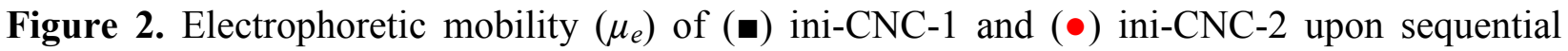
addition of polymerization reagents and during polymer brush growth. Note: Error bars are smaller than the symbols in most cases. Insert shows $t=5 \mathrm{~min}$ to $1340 \mathrm{~min}$ at high zoom.

In order to ensure that the trends observed in electrophoresis were not due to changes in the dielectric properties of the aqueous medium during SI-ATRP, conductivity was measured in situ, as presented in Figure 3. We expected that the addition of $2 \mu \mathrm{mol} / \mathrm{mL} \mathrm{CuCl}$ activator would have little effect on the dielectric constant of the medium, ${ }^{57}$ due to its low solubility in water. An initial decrease in conductivity was noted during the first 10 minutes of SI-ATRP, which was 
likely caused by the growth of neutral PDMAM brushes that insulated charges. Following this initial drop, the conductivity remained stable for 2 hours, followed by a steady increase due to disproportionation of $\mathrm{CuCl} / \mathrm{PMDETA}$ to $\mathrm{Cu}^{0}$ and $\mathrm{CuX}_{2} / \mathrm{PMDETA}$ species, generating $\mathrm{Cu}^{2+}$ and $\mathrm{X}^{-}$ions, in agreement with Nguyen et al. ${ }^{53}$ Therefore, trends observed in electrophoresis experiments during the first $120 \mathrm{~min}$ (Figure 2) were probably unaffected by the dielectric properties of the media and disproportionation of $\mathrm{CuCl}$, since the conductivity remained the same during this time period (Figure 3).

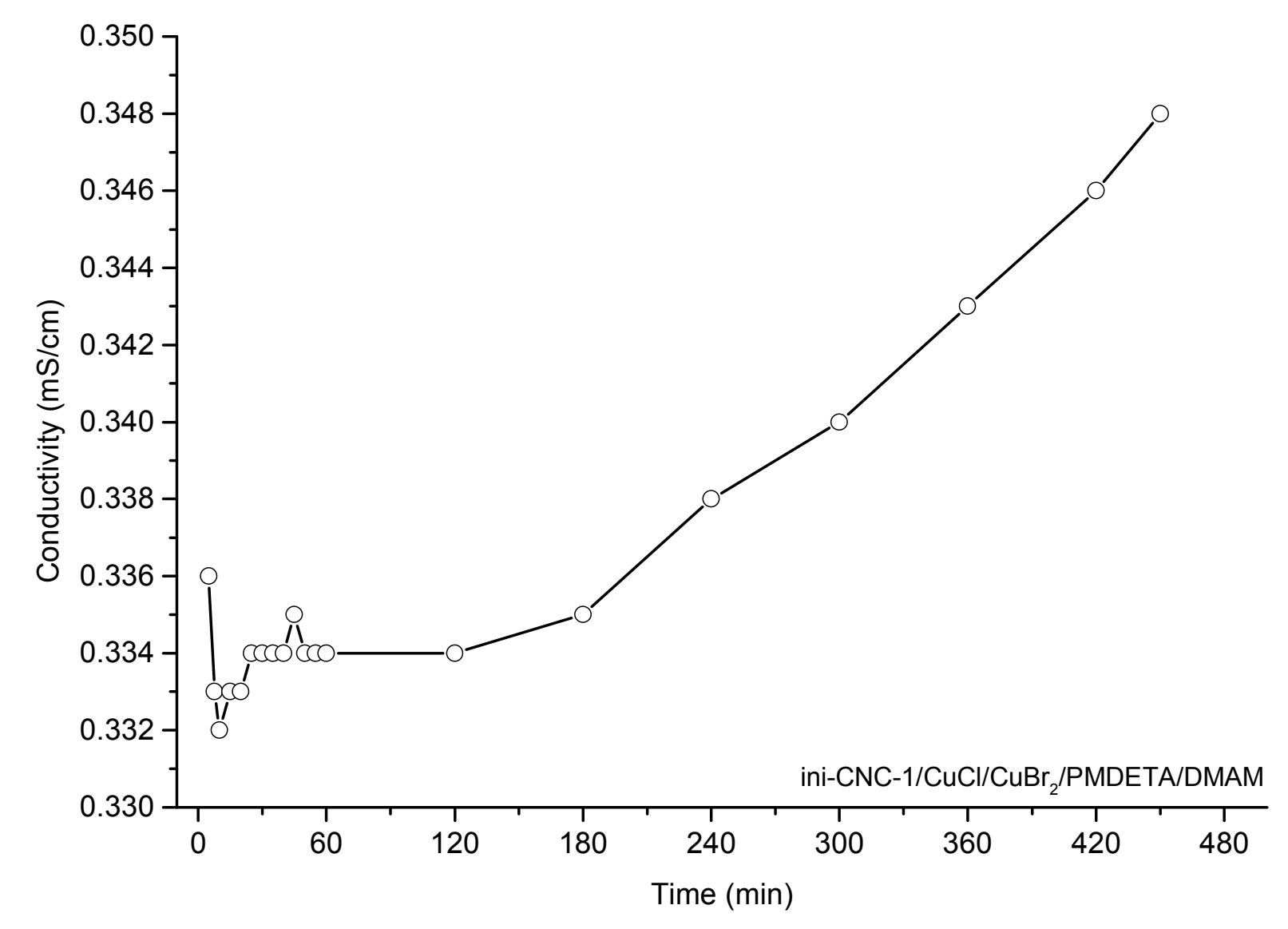

Figure 3. In situ conductivity measured during SI-ATRP of DMAM from ini-CNC-1. 
Next, the PDMAM grafts were cleaved from both $\mathrm{CNC}$ substrates by alkaline hydrolysis $^{35}$ (Scheme 1) and subjected to GPC analysis. GPC traces of PDMAM degrafted from substrates $\mathrm{CNC}-1$ and $\mathrm{CNC}-2$ are shown in Figure 4 and the corresponding molecular weights $\left(M_{n}, M_{w}\right)$ and polydispersities $\left(M_{w} / M_{n}\right)$ are summarized in Table 1. An example of an FTIR spectrum of cleaved PDMAM grafts compared to the DMAM monomer are shown in Figure S5, which confirmed that dimethylamino groups were stable under these hydrolysis conditions. PDMAM brushes cleaved from CNC-1 were determined to have a $M_{n}$ of $420 \mathrm{kDa}$ with the GPC trace showing a small fraction of dead chains at high retention times, likely a result of early terminations. On the other hand, the GPC trace of brushes cleaved from CNC-2 was more symmetrical, indicating slightly lower polydispersity and perhaps less influence of termination events. Furthermore, the $M_{n}$ of PDMAM cleaved from CNC-2 was $>100 \mathrm{kDa}$ higher $(530 \mathrm{kDa})$ than those cleaved from CNC-1. Utilizing the change in carbon content from the results of elemental analysis, ${ }^{49}$ PDMAM brush grafting densities $(\sigma)$ and thus, initiator efficiencies $\left(\sigma / \sigma_{i}\right)$ were calculated (Table 1), taking into account differences in effective surface area due to aggregation of CNC-2. Although the initiator grafting density $\left(\sigma_{i}\right)$ was 5 times higher on $\mathrm{CNC}-2$ compared to the CNC-1 substrate, in both cases, PDMAM grafting density $(\sigma)$ was determined to be 0.002 chains $/ \mathrm{nm}^{2}$. This was an evident indication that increased surface initiator efficiency was obtained from the highly charged CNC-1 substrate compared to CNC-2 (10\% and $2 \%$, respectively), in agreement with similar studies of other charged polymeric substrates. ${ }^{14,15,17}$ To the best of our knowledge, this is the first time that high molecular weight $\left(M_{n}>150 \mathrm{kDa}\right)$ PDMAM has been obtained through a Cu-mediated radical polymerization system at such dilute monomer concentrations, i.e. $2 \%$ wt. or $202 \mathrm{mM}^{14-17,52,53,58,59}$ This suggests the potential of charged nanocolloids as sacrificial substrates for the ultrafast synthesis of high molecular weight polyacrylamides with $M_{w} / M_{n} \leq 1.5$. An initial attempt was made to obtain higher initiator 
efficiency and monomer conversion from the CNC-2 substrate by decreasing the amount of $\mathrm{CuBr}_{2}$ deactivator (Table S2). This experiment, however, suffered from high polydispersity $\left(M_{w} / M_{n}=2.4\right)($ Figure S8) and only a slightly higher initiator efficiency of $4 \%$. Moreover, DLS displayed a peak at $\sim 20 \mathrm{~nm}$ that was attributed to $\mathrm{Cu}^{0}$ nanoparticles likely due to some degree of $\mathrm{CuCl}$ disproportionation (Figure S8), which could have further complicated electrophoresis experiments. PDMAM brushes were also cleaved from quaternary ammonium-functionalized CNC-3 substrates for GPC analysis (Figure S10), resulting in a $M_{n}$ of $160 \mathrm{kDa}$ and $M_{w} / M_{n}$ of 1.2 , which indicated that SI-ATRP was clearly affected by colloidal aggregation and the presence of cationic surface charges, as compared to the much higher $M_{n}$ obtained in the presence of the anionic surface charges of CNC-1 and CNC-2.
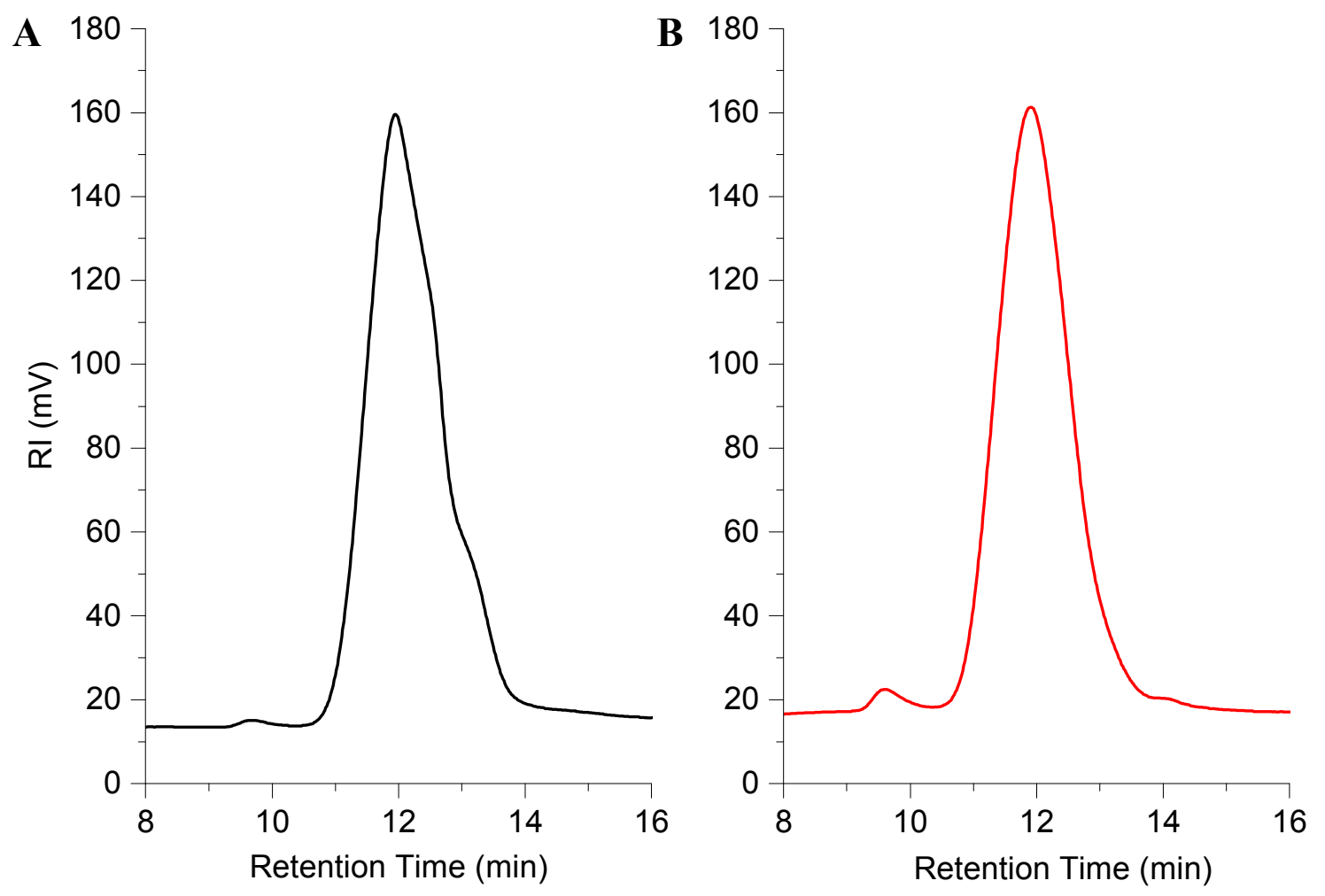

Figure 4. GPC traces of PDMAM cleaved from (A) CNC-1 and (B) CNC-2. 
The results of this study suggest an effect of CNC surface charge on initiator efficiency of SI-ATRP, as observed for other charged polymeric substrates. ${ }^{14,15,17}$ A simple qualitative model, shown in Scheme 3, can be used to explain the increased surface initiator efficiency for PDMAM brush growth from highly charged CNCs. In the case of CNCs containing a high density of sulfate half-ester groups, dissociated $\mathrm{Cu}^{2+} /$ PMDETA complexes likely formed an immobilized "Stern" layer to neutralize anionic surface charges, ${ }^{13}$ with an outer diffuse layer of $\mathrm{Cu}^{2+} / \mathrm{PMDETA}, \mathrm{CuCl} / \mathrm{PMDETA}$ and $\mathrm{Br}^{-}$ions, yielding an electrical double layer (EDL) with a relatively short Debye length. CNCs with a low density of anionic surface charges led to an EDL of thicker Debye length and less deactivator species immobilized or associated to CNC surfaces. While the $M_{n}$ of PDMAM cleaved from CNC-2 was higher than those cleaved from CNC-1, the initiator efficiency was higher from $\mathrm{CNC}-1$, as determined by electrophoresis, ${ }^{1} \mathrm{H}$ NMR spectroscopy and elemental analysis. This is explained by overall enrichment of catalytic species at highly charged CNC interfaces. ${ }^{14-17}$ Moreover, the decreased availability of deactivator species that were associated with sulfate groups likely contributed to the inefficient deactivation shown in GPC traces. Therefore, although anionic surface charges increased the initiator efficiency of $\mathrm{Cu}-$ mediated SI-ATRP, CNCs with lower surface charge density did not suffer the same extent of early chain terminations, as a result of more "free" deactivator species. 
Scheme 3. Qualitative model of the interfacial region prior to polymer brush growth from cellulose nanocrystals with high (CNC-1) and low (CNC-2) surface density of sulfate half-ester groups. ( $\mathbf{\uparrow}=$ initiator, $\mathrm{L}=$ ligand, $\kappa^{-1}=$ Debye length)

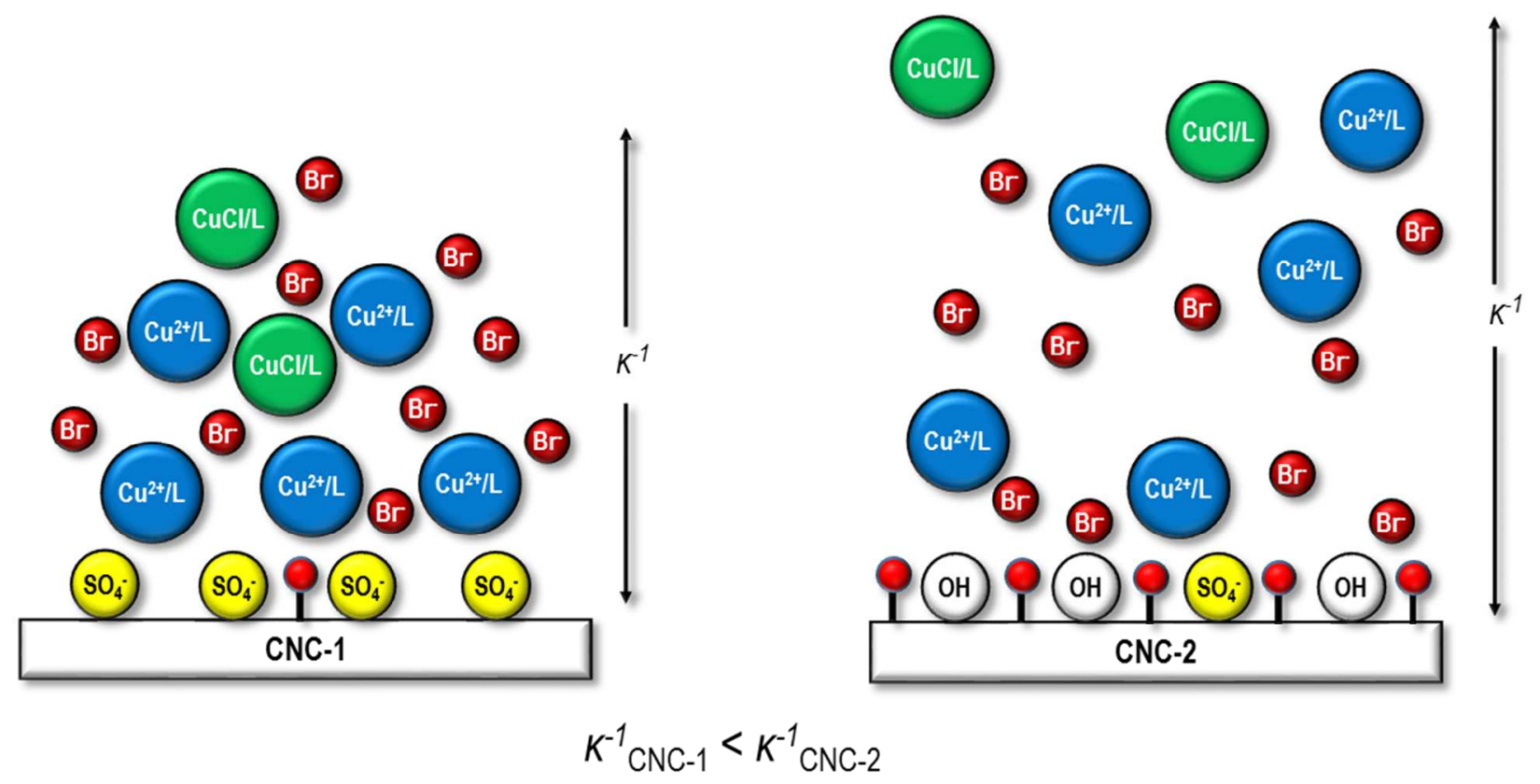

\section{CONCLUSIONS}

Overall, the results indicated that anionic surface sulfate half-ester groups have an effect on the surface initiator efficiency in aqueous SI-ATRP. Specifically, electrostatic interactions likely caused overall enrichment of catalytic species at highly charged CNC interfaces leading to higher initiator efficiency. ${ }^{14-17}$ However, this came at the expense of inefficient deactivation of growing polymer chains due to immobilization of divalent $\mathrm{Cu}^{2+} / \mathrm{L}$ complexes. In addition, the high surface charge density of CNCs lead to lower initiator grafting density, lower molecular weight and higher polydispersity of PDMAM brushes. Overall, these results suggest that surface charge offers a means to further manipulate $\mathrm{Cu}$-mediated SI-CRP in polar media and the possibility to rapidly obtain high molecular weight polyacrylamides with $M_{w} / M_{n} \leq 1.5$. The 
results presented here could also have implications for conducting $\mathrm{Cu}$-mediated SI-CRP from other substrates presenting anionic surface charges, e.g. silicon wafers or silica nanoparticles in which unreacted silanol groups are dissociated at or above neutral $\mathrm{pH}^{60}$ Surface charge could also contribute to the disparity observed in polymer brush growth kinetics from silica versus gold. ${ }^{61}$ Finally, surface chemistry is expected to also play a role in comparisons of free polymers produced simultaneously via sacrificial initiators during $\mathrm{Cu}$-mediated SI-CRP in polar media.

\section{ASSOCIATED CONTENT}

\section{Supporting Information}

Table of polymerization conditions for CNC-g-PDMAM-2.1 samples, elemental analysis data, DLS of sulfated vs. desulfated CNCs, AFM image of CNCs, ATR-FTIR of DMAM and cleaved PDMAM, TGA curves, DLS and GPC traces of CNC-g-PDMAM-2.1 and CNC-g-PDMAM-3. This material is available free of charge via the Internet at http://pubs.acs.org.

\section{AUTHOR INFORMATION}

\section{Corresponding Author}

*Email: justin.zoppe@epfl.ch, Phone: + 4121693 4872, Fax: + 41216935650

\section{Author Contributions}

The manuscript was written through contributions of all authors. All authors have given approval to the final version of the manuscript.

\section{Funding Sources}

This project was supported in part by an EPFL Fellowship cofunded by Marie Curie from the European Union's Seventh Framework Programme (grant agreement no. 291771). 


\section{ACKNOWLEDGMENT}

The authors would like to express their gratitude to Jacques Henri Morisod for GPC analysis and John Moraes and Ioana Konz for assistance with ${ }^{1} \mathrm{H}$ NMR analysis. Thanks are given to the Laboratorium für Organische Chemie (ETH-Zürich) for elemental analysis.

\section{ABBREVIATIONS}

CNCs, cellulose nanocrystals; PDMAM, poly(N,N-dimethylacrylamide); SI-ATRP, surfaceinitiated atom transfer radical polymerization; SI-CRP, surface-initiated controlled radical polymerization; SI-RDRP, surface-initiated reversible deactivation radical polymerization; EDL, electrical double layer; GTMAC, glycidyltrimethylammonium chloride; PMDETA, $N, N, N^{\prime}, N^{\prime \prime}, N^{\prime \prime}$-pentamethyldiethylenetriamine; BIBB, $\alpha$-bromoisobutyryl bromide

\section{REFERENCES}

(1) Barbey, R.; Lavanant, L.; Paripovic, D.; Schüwer, N.; Sugnaux, C.; Tugulu, S.; Klok, H.A., Chem. Rev. 2009, 109, 5437-5527.

(2) Edmondson, S.; Osborne, V. L.; Huck, W. T. S., Chem. Soc. Rev. 2004, 33, 14-22.

(3) Zhao, B.; Brittain, W. J., Prog. Polym. Sci. 2000, 25, 677-710.

(4) Braunecker, W. A.; Tsarevsky, N. V.; Gennaro, A.; Matyjaszewski, K., Macromolecules 2009, 42, 6348-6360.

(5) Huang, W. X.; Kim, J. B.; Bruening, M. L.; Baker, G. L., Macromolecules 2002, 35 , 1175-1179.

(6) Simakova, A.; Averick, S. E.; Konkolewicz, D.; Matyjaszewski, K., Macromolecules 2012, 45, 6371-6379.

(7) Tsarevsky, N. V.; Pintauer, T.; Matyjaszewski, K., Macromolecules 2004, 37, 9768-9778.

(8) Konkolewicz, D.; Krys, P.; Góis, J. R.; Mendonça, P. V.; Zhong, M.; Wang, Y.; Gennaro, A.; Isse, A. A.; Fantin, M.; Matyjaszewski, K., Macromolecules 2014, 47, 560-570.

(9) Konkolewicz, D.; Wang, Y.; Zhong, M.; Krys, P.; Isse, A. A.; Gennaro, A.; Matyjaszewski, K., Macromolecules 2013, 46, 8749-8772.

(10) Percec, V.; Guliashvili, T.; Ladislaw, J. S.; Wistrand, A.; Stjerndahl, A.; Sienkowska, M. J.; Monteiro, M. J.; Sahoo, S., J. Am. Chem. Soc. 2006, 128, 14156-14165. 
(11) Rosen, B. M.; Percec, V., Chem. Rev. 2009, 109, 5069-5119.

(12) Matyjaszewski, K.; Coca, S.; Gaynor, S. G.; Wei, M. L.; Woodworth, B. E., Macromolecules 1997, 30, 7348-7350.

(13) Hiemenz, P. C.; Rajagopalan, R., Principles of colloid and surface chemistry. 3rd ed.; CRC Press: New York, 1997.

(14) Jayachandran, K. N.; Takacs-Cox, A.; Brooks, D. E., Macromolecules 2002, 35, 42474257.

(15) Kizhakkedathu, J. N.; Brooks, D. E., Macromolecules 2003, 36, 591-598.

(16) Kizhakkedathu, J. N.; Norris-Jones, R.; Brooks, D. E., Macromolecules 2004, 37, 734743.

(17) Zou, Y. Q.; Kizhakkedathu, J. N.; Brooks, D. E., Macromolecules 2009, 42, 3258-3268.

(18) Hunter, R. J., Zeta Potential in colloids Science: Principles and Applications. Academic Press: New York, 1981.

(19) Brooks, D. E., J. Colloid Interface Sci. 1973, 43, 687-699.

(20) Brooks, D. E.; Seaman, G. V. F., J. Colloid Interface Sci. 1973, 43, 670-686.

(21) Weber, K.; Osborn, M., J. Biol. Chem. 1969, 244, 4406-\&.

(22) Habibi, Y.; Lucia, L. A.; Rojas, O. J., Chem. Rev. 2010, 110, 3479-3500.

(23) Klemm, D.; Kramer, F.; Moritz, S.; Lindstroem, T.; Ankerfors, M.; Gray, D.; Dorris, A., Angew. Chem., Int. Ed. 2011, 50, 5438-5466.

(24) Habibi, Y., Chem. Soc. Rev. 2014, 43, 1519-1542.

(25) Jiang, F.; Esker, A. R.; Roman, M., Langmuir 2010, 26, 17919-17925.

(26) Kloser, E.; Gray, D. G., Langmuir 2010, 26, 13450-13456.

(27) Hasani, M.; Cranston, E. D.; Westman, G.; Gray, D. G., Soft Matter 2008, 4, 2238-2244.

(28) Morandi, G.; Heath, L.; Thielemans, W., Langmuir 2009, 25, 8280-8286.

(29) Morandi, G.; Thielemans, W., Polymer Chemistry 2012, 3, 1402-1407.

(30) Yi, J.; Xu, Q. X.; Zhang, X. F.; Zhang, H. L., Polymer 2008, 49, 4406-4412.

(31) Majoinen, J.; Walther, A.; McKee, J. R.; Kontturi, E.; Aseyev, V.; Malho, J. M.; Ruokolainen, J.; Ikkala, O., Biomacromolecules 2011, 12, 2997-3006.

(32) Xu, Q. X.; Yi, J.; Zhang, X. F.; Zhang, H. L., Eur. Polym. J. 2008, 44, 2830-2837.

(33) Yi, J.; Xu, Q.; Zhang, X.; Zhang, H., Cellulose 2009, 16, 989-997. 
(34) Chen, X.; Huang, L.; Sun, H.-J.; Cheng, S. Z. D.; Zhu, M.; Yang, G., Macromol. Rapid Commun. 2014, 35, 579-584.

(35) Zoppe, J. O.; Habibi, Y.; Rojas, O. J.; Venditti, R. A.; Johansson, L.-S.; Efimenko, K.; Osterberg, M.; Laine, J., Biomacromolecules 2010, 11, 2683-2691.

(36) Zoppe, J. O.; Osterberg, M.; Venditti, R. A.; Laine, J.; Rojas, O. J., Biomacromolecules 2011, 12, 2788-2796.

(37) Zoppe, J. O.; Venditti, R. A.; Rojas, O. J., J. Colloid Interface Sci. 2012, 369, 202-209.

(38) Zeinali, E.; Haddadi-Asl, V.; Roghani-Mamaqani, H., RSC Adv. 2014, 4, 31428-31442.

(39) Habibi, Y.; Chanzy, H.; Vignon, M. R., Cellulose 2006, 13, 679-687.

(40) Lin, N.; Dufresne, A., Nanoscale 2014, 6, 5384-5393.

(41) Zoppe, J. O.; Ruottinen, V.; Ruotsalainen, J.; Ronkko, S.; Johansson, L. S.; Hinkkanen, A.; Jarvinen, K.; Seppala, J., Biomacromolecules 2014, 15, 1534-1542.

(42) Cherhal, F.; Cousin, F.; Capron, I., Langmuir 2015, 31, 5596-5602.

(43) Sehaqui, H.; de Larraya, U. P.; Tingaut, P.; Zimmermann, T., Soft Matter 2015, 11, 52945300 .

(44) Carlmark, A.; Malmstrom, E., J. Am. Chem. Soc. 2002, 124, 900-901.

(45) Jennings, B. R.; Parslow, K., Proc. R. Soc. London, Ser. A 1988, 419, 137-149.

(46) Beck, S.; Methot, M.; Bouchard, J., Cellulose 2015, 22, 101-116.

(47) Zoppe, J. O.; Johansson, L.-S.; Seppala, J., Carbohydr. Polym. 2015, 126, 23-31.

(48) Gu, J.; Catchmark, J. M.; Kaiser, E. Q.; Archibald, D. D., Carbohydr. Polym. 2013, 92, 1809-1816.

(49) Bartholome, C.; Beyou, E.; Bourgeat-Lami, E.; Chaumont, P.; Zydowicz, N., Macromolecules 2003, 36, 7946-7952.

(50) Behling, R. E.; Williams, B. A.; Staade, B. L.; Wolf, L. M.; Cochran, E. W., Macromolecules 2009, 42, 1867-1872.

(51) Brittain, W. J.; Minko, S., J. Polym. Sci., Part A: Polym. Chem. 2007, 45, 3505-3512.

(52) Rademacher, J. T.; Baum, R.; Pallack, M. E.; Brittain, W. J.; Simonsick, W. J., Macromolecules 2000, 33, 284-288.

(53) Nguyen, N. H.; Rosen, B. M.; Percec, V., J. Polym. Sci., Part A: Polym. Chem. 2010, 48, 1752-1763. 
(54) Matyjaszewski, K.; Shipp, D. A.; Wang, J. L.; Grimaud, T.; Patten, T. E., Macromolecules 1998, 31, 6836-6840.

(55) Vorwerg, L.; Antonietti, M.; Tauer, K., Colloid Surface A 1999, 150, 129-135.

(56) Grossman, P. D.; Soane, D. S., Anal. Chem. 1990, 62, 1592-1596.

(57) Hasted, J. B.; Ritson, D. M.; Collie, C. H., J. Chem. Phys. 1948, 16, 1-21.

(58) Appel, E. A.; del Barrio, J.; Loh, X. J.; Dyson, J.; Scherman, O. A., J. Polym. Sci., Part A: Polym. Chem. 2012, 50, 181-186.

(59) Millard, P. E.; Barner, L.; Reinhardt, J.; Buchmeiser, M. R.; Barner-Kowollik, C.; Muller, A. H. E., Polymer 2010, 51, 4319-4328.

(60) Behrens, S. H.; Grier, D. G., J. Chem. Phys. 2001, 115, 6716-6721.

(61) Saha, S.; Bruening, M. L.; Baker, G. L., ACS Appl. Mater. Interfaces 2011, 3, 3042-3048. 


\section{FOR TABLE OF CONTENTS USE ONLY}

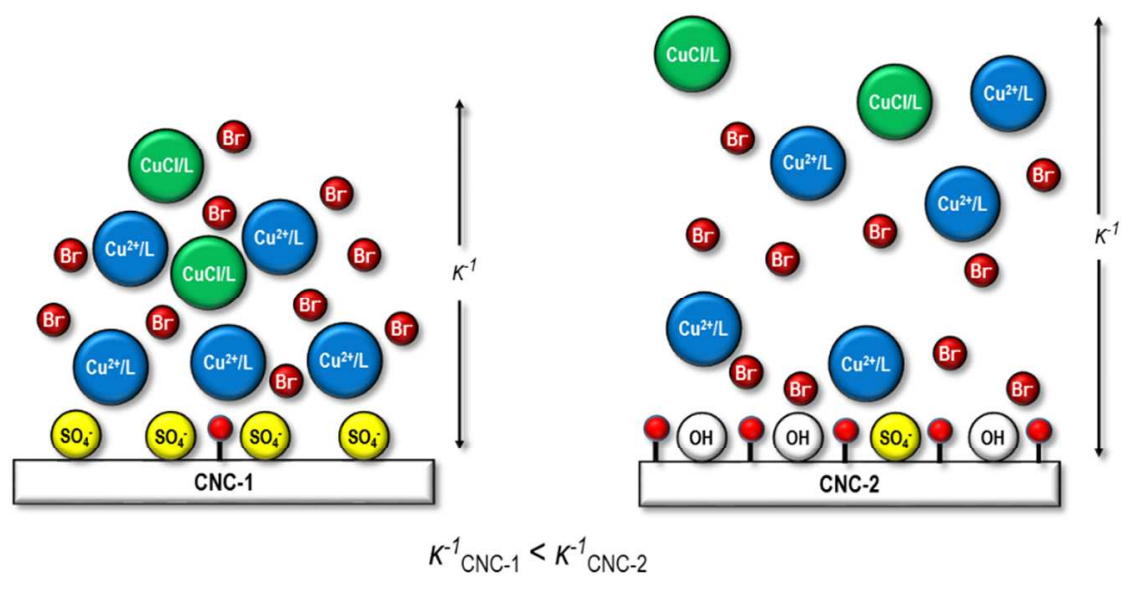

20

21

22

23

24

25

26

27

28

29

30

31

32

33

34

35

36

37

38

39

40

41

42

43

44

45

46

47

48

49

50

51

52

53

54

55

56

57

58

59

60 